\title{
Informed consent in inflammatory bowel disease: a necessity in real-world clinical practice
}

\author{
Nikolaos Kyriakos ${ }^{a}$, Apostolis Papaefthymiou ${ }^{a}$, Marios Giakoumis ${ }^{a}$, George latropoulos ${ }^{b}$, \\ Gerasimos Mantzaris', Christos Liatsos ${ }^{\mathrm{a}}$
}

401 General Army Hospital of Athens, Greece; Olivia Newton-John Cancer and Wellness Centre, Austin Health, Melbourne, Australia; General Hospital of Athens "Evangelismos-Ophtalmiatreion Athinon-Polykliniki", Athens, Greece

\section{Abstract}

\section{Introduction}

A patient's knowledge, understanding and approval of medical interventions, particularly of invasive procedures, is ethically,

${ }^{\mathrm{a}}$ Gastroenterology Department, 401 General Army Hospital of Athens, Greece (Nikolaos Kyriakos, Apostolis Papaefthymiou, Marios Giakoumis, Christos Liatsos); ${ }^{\mathrm{b}}$ Medical Oncology Department, Olivia Newton-John Cancer and Wellness Centre, Austin Health, Melbourne, Australia (George Iatropoulos); 'Gastroenterology Department, General Hospital of Athens "Evangelismos-Ophtalmiatreion AthinonPolykliniki”, Athens, Greece (Gerasimos Mantzaris)

Conflict of Interest: None

Correspondence to: Christos Liatsos, MD, PhD, FEBGH, Director of the Gastroenterology Department, 401 General Army Hospital of Athens, Greece, Mesogeion Ave. 130 and Katechaki, 11525, Athens, Greece, e-mail: cliatsos@yahoo.com

Received 25 October 2020; accepted 8 March 2021; published online 3 June 2021

DOI: https://doi.org/10.20524/aog.2021.0635 practically and legally required with respect to human rights of autonomy and self-determination. Informed consent (IC) is defined as the "process of communication between a patient and physician that results in the patient's authorization or agreement to undergo a specific medical intervention" [1]. The American College of Physicians describes IC as "a communication process in which the patient's diagnosis, the nature, purpose, risks and benefits of the proposed procedure, and the nature, risks, and benefits of alternatives to the proposed procedure, including the option of not receiving any treatment, should be discussed" [2].

Each medical procedure in real-world settings is characterized by a respective set of unique circumstances. Thus, applying a blanket IC process across all of these circumstances is extremely difficult. Research into IC in the medical ethics literature is relatively new, and although it is ethically and legally mandated by the fiduciary responsibilities of the patient-physician relationship, there are still many persisting inadequacies in this research field.

This review aims to summarize the most recent data in the literature regarding the IC procedure, and to suggest ways it 
may be applied appropriately to patients with inflammatory bowel disease (IBD) in real-world clinical practice, with respect to legal and ethical principles.

\section{History of IC}

The concept that patients have the right to be informed and to consent to their physician's therapeutic decisions was not part of medical routine until the second half of the $20^{\text {th }}$ century. In Ancient Greece, medical practitioners used to swear to their gods according to the Hippocratic Oath, that they would treat patients based on their ability and judgment, but no consideration was given to issues of either consent or selfdetermination by patients [3]. Even in the $19^{\text {th }}$ century (1847), the American Medical Association declared in its first Code of Ethics [4], that "obedience of patients to the prescriptions of their physician should be prompt and implicit" and that "they should never permit their own crude opinions to influence their attention to their physicians".

In the second half of the twentieth century, a remarkable series of cases brought IC to the attention of both lawyers and physicians. The term "informed consent" was first introduced in the Salgo v. Leland Stanford case in 1957 [5] and then elaborated in a lengthier opinion in the Kansas Supreme Court in the case of Natanson v. Kline (1960) [6]. In the latter case, a patient suffered severe injuries from cobalt radiation administered subsequent to a mastectomy for breast cancer, and the judge decided that it was necessary "to disclose and explain to the patient, in simple language, the nature of the ailment, the nature of the proposed treatment, the probability of success or alternatives, and perhaps the risks of unfortunate results and unforeseen conditions within the body" [6].

There followed an increasing trend towards patients' independent decision-making, implemented via modifications of both the laws and the standards of IC over the next 5060 years. In Europe, the Declaration of Lisbon in 1981 by the World Medical Association [7] and the Convention on Human Rights and Biomedicine in Oviedo in 1998, supported by the member States of the Council of Europe, the other States and the European Community [8], established the need for patients to provide informed and voluntary consent before undergoing any health-related intervention. The decisions of the Convention in Oviedo were approved and have been part of the national laws of all European Countries since. As a result, physicians' failure or reluctance to request and obtain IC from their patients is now considered under the legal domain of negligence.

\section{Goals and validity criteria of IC}

A valid IC procedure has to ensure 3 goals: the legal goal of protecting patients' rights, the ethical goal of supporting autonomous decision-making, and the operational goal of providing efficient health care [9]. The reliability and validity of the IC process depends mainly on how much respect is given to patients' autonomy and self-determination-meaning adherence to patients' thoughts and decisions without any attempt at manipulation - and on how appropriate and rigorous is the disclosure concerning the proposed medical intervention and its benefits, potential hazards, alternative treatments and outcomes if the patient remains untreated [10,11]. Various committees, hospital boards, but also experts in the IC process, agree on at least 4 basic criteria for an adequate IC and morally valid decision making process: i) competence of patient to understand and to decide; ii) disclosure of essential information and recommendation of a plan; iii) comprehension of proposed terms; and iv) voluntary decision making [9,12-14].

\section{Considerations and challenges of a valid IC}

Although IChas been established in clinical practice, there are still many challenges to its application that need consideration. These are the specificity and complexity of medical information being provided, which could result in miscomprehension, patients' decision-making incompetence due to psychological and physical stress originating from their disease, physicians' uncertainty in combination with the easy access patients have to medical information from controversial sources, legal concerns of the physician, and, finally, the unresolved dilemma about the necessity of IC documentation [10,11].

\section{Comprehension of material information}

The most challenging issue in the IC process, even for a skillful physician, is to present complex medical information to the patient in both a "comprehensive way" and in "simple words". Before quoting confusing details, physicians should apply a patient-centered approach, and estimate their patients' perception skills, and particularly their numeracy and their risk and health literacy. "Numeracy" is the ability to understand and work with numbers, while "risk literacy" is the ability to accurately assess and understand risk information [15]. Patients with low numeracy skills face challenges in appropriately balancing the benefits and risks of medical treatments and interventions, and tend to overestimate their personal risk of suffering from several diseases [16].

Numeracy and risk literacy are measurable terms nowadays, with the most commonly used assessment instrument being the 11-question test developed by Schwartz, Woloshin, Black and Welch in 1997 [17], which was modified by Lipkus, Samsa, and Rimer in 2001 [18]. This test assesses practical knowledge of basic math and probabilities via questions like "if the chance of getting a disease is $10 \%$ how many people would be expected to get the disease", etc. [18].

"Health literacy" is the capacity to obtain, communicate, process and understand basic health information and services to make appropriate health decisions [19]. Limited health literacy leads to a reduced ability to interpret health messages and to follow preventive care policies [20]. Unfortunately, in a population-based study regarding health literacy skills in the 
USA, researchers concluded that only $12 \%$ of adult patients were competent enough in health literacy to understand and manage health information effectively [21].

In this regard, the role of the physician in improving patients' understanding requires specialist attention. For example, medication counseling, using simple language and a pictogrambased approach, leads to both fewer medication-dosing errors (5.4 \% vs. $47.8 \%, \mathrm{P}<0.001$ ) and better compliance, compared to standard medication instructions ( $38 \%$ vs. 9.3\%, $\mathrm{P}=0.002)$ [22]. Accumulating data suggests that simple visualization aids can remarkably improve complex medical directions [23]. Visual aids are simple graphs representing numerical values of probability and include icon arrays, bar and line charts; they have been proven to be beneficial in communicating healthrelated risk information [24-26]. The efficacy of these methods depends on their format. Specifically, static icon arrays and bar graphs were found to be the most effective means to improve the understanding of risk and benefit balance in patients with both low and high numeracy skills [27]. A recent systematic review of 52 studies that evaluated a variety of interventions to improve patient comprehension in IC for medical and surgical procedures found strong evidence that written material, audiovisual tools, multicomponent interventions, interactive digital interventions and verbal discussion with test/feedback or teach-back interventions improve patient understanding [28].

Physicians should periodically assess and update the readability and suitability of written material. The words, syllables and sentences used in written material can be evaluated using formulas such as the Flesch Reading Ease Score (FRES), which is the most commonly used.

$$
\begin{gathered}
\text { Flesch Reading Ease Score } \\
206.835-1.015\left(\frac{\text { total words }}{\text { total sentences }}\right)-84.6\left(\frac{\text { total syllables }}{\text { total words }}\right)
\end{gathered}
$$

High FRES scores (maximum score: 100) predict optimal comprehension, while a score of more than 60 is considered an acceptable cutoff [29-31]. Various USA organizations have concluded that the readability of healthcare materials for patients, such as consent forms, should be written at a level that can be understood by a 12-year-old child (corresponding FRES score for this level of education is 60-69) [32].

\section{Disclosure of treatment risks}

The presentation of possible complications of therapy is a double-edged sword. Those in favor of extensive disclosures about treatment and its risks believe that this is an ethical obligation, improves compliance and aids the early recognition of side-effects [33-35]. Those reluctant to provide patients with detailed information believe that such disclosures may increase patients' anxiety [36], and lead to the refusal of treatment [37,38]. As Berg et al. [39] note: ".the physician must walk a fine line between providing pertinent risk information and overwhelming the patient with frightening statistics".

In a study concerning the impact of disclosing information on both the patient understanding and the medical outcomes of a prescribed drug (carbamazepine), the researchers concluded that giving patients extensive information about the drugs they are prescribed does not incur negative consequences [40]. In addition, in a survey of cancer patients undergoing radiotherapy, $44 \%$ of them felt that information about severe side-effects affecting quality of life must be provided to them, even if the risk is $0.1 \%$ [41]. In conclusion, a reluctance to refer to probable side-effects of treatment may be unfounded, both ethically and practically $[13,39]$.

\section{Documentation of IC}

Despite the law's clarity about the need for IC before any medical intervention, the way that IC is provided is not concrete. For example, in Greece, IC, in accordance with the law and the National Code of Medical Ethics Reference [42], must be documented (in written form) and signed only in 3 situations: 1. for participation in clinical research (clinical trials); 2. for organ and tissue removal from living donors for transplantation purposes; and 3. for in vitro fertilization. Similar regulations apply elsewhere, modified depending on the respective legal systems of the country.

In any case, it has been shown that the validity of consent does not depend on the form in which it is given. Written consent merely serves as evidence of consent: if the elements of adequate capacity, appropriate information and voluntariness have not been satisfied, a signature on a form will not make the consent valid $[41,43]$. Cases have come to court where the existence of consent forms with standard wording was not recognized as a sufficient explanation [44].

On the other hand, prosecution is rarely successful when there is evidence that the clinician has made an effort in good faith to inform the patient. Indeed, the risk of litigation often depends on patient dissatisfaction due to lack of communication with the physician [45]. Primary care physicians who routinely check their patients' understanding as part of an IC process are at lower risk for law suits [46].

Despite the above, there are legal issues for the healthcare provider. It is in this case that documentation by way of an IC form is useful. If consent has been given validly, the lack of a completed form is no bar to treatment, but a form can be important evidence of such consent. Signed consent acts as a prompt to ensure that a patient's agreement has not been assumed but discussed and voluntarily provided [38].

The USA Veterans Health Administration strongly recommends that written consent be used for complicated procedures, which are those that produce significant pain or discomfort, or require sedation, anesthesia or intravenous analgesia, that have a significant risk of complications or morbidity, and that require injections into a joint space or body cavity [47]. Verbal consent is sufficient after adequate information has been provided for treatments and procedures that are considered low risk, such as administration of drugs, blood exams, or x-rays [47].

The current clinical practice in noninvasive specialties is the adoption of IC according to medical deontology codes, without the need for a patient's signature. Signed IC forms are needed for more invasive or risky therapeutic procedures, as 
mentioned above. In this regard, the rheumatologist author of a recent review stated the following: "...the obligation of a signed IC provided by the patient for every medical procedure is neither reasonable nor practical and its adoption in routine medical care practice would make medical intervention bureaucratic" [48]. In a different approach, Oncology and Hematology Societies suggest to their members, though it is not legally required, that they should document their consent conversations through a written consent form reviewed with the patient and signed by him/her, or through a detailed note in the patient's medical records $[49,50]$. Clinicians and researchers alike tend to agree that consent forms cannot replace direct communication between physician and patient and that IC needs to be a careful, thorough and honest process that develops over time, rather than a paper-signing ritual.

\section{IC for IBD patients}

The issue of IC for IBD patients has never been studied before, outside the field of clinical trials [51]. One related study highlights the importance of communicating the benefits and risks of IBD therapy to pediatric patients and their families [52], while another from the USA studied the gastroenterologists' method of sharing decision making (SDM) for IBD patients [53]. Both studies agree that the SDM process increased patients' satisfaction. Interestingly, the vast majority of gastroenterologists (80\%) tried to introduce a form of SDM, but only $12 \%$ yielded a systematic, consistent, and formally documented approach to SDM. Lack of time (74\%), reimbursement (70\%), and tools (51\%) were the main barriers to applying SDM [53]. In addition, Siegel suggested tools to communicate risks of immunomodulators and biologic therapy to IBD patients and to make medical data easier to understand, in order to take informed medical decisions that fit with their personal preferences for treatment [54].

An emerging question is whether treatment with immunomodulators, biologics, or even mesalamine, needs an IC. As thoroughly explained above, patient consent is an ethical and practical prerequisite before any medical treatment, and only the absence of risk justifies not asking for consent. Any drug, however, even the most harmless, carries a potential risk. As a consequence, consent appears to be mandatory, especially in drugs like immunosuppressants and biologics, which may carry quite serious, though rare, side-effects. Nevertheless, IC without adequate information is invalid and immoral.

The field of IBD has its unique characteristics that warrant the adoption of the IC process in daily clinical practice. First of all, the age of most IBD patients (many of whom are adolescents) and the particular characteristics of this ageintense emotions, easy disappointment or excitement, refusal to accept their medical situation, desire for no restrictions in daily life, etc.- - prevent them from accepting their physicians' clinical recommendations without question. When working with minors, parents' approval and IC are mandatory. However, nowadays there is a plethora of therapeutic options for IBD patients, all of which need to be communicated in order for the patient to be able to make an informed decision. The often high educational and socioeconomic level of these patients means that they have more information from various sources at their fingertips, including internet, patients' associations or another gastroenterologist's opinion. As a consequence, they need more detailed explanations to help make therapeutic decisions. Finally, IBD drugs carry rare but significant risks, including cancer, lymphoma and exacerbation of latent infections or demyelinating disorders, and, as a result, it is ethically and legally unacceptable not to precede prescription with comprehensive information about the potential for adverse events.

With the traditional paternalistic relationship between doctor and patient a thing of the past, and the emergence of the joint decision-making process in patient care, a more contemporary approach should be adopted by IBD physicians. They should ensure that the IC process is followed before prescribing and administering pharmaceutical treatment to their patients, in order to fulfill the 4 above-mentioned criteria: 1. capacity; 2 . disclosure; 3 . comprehension; and 4. voluntariness of patient. Moreover, in current clinical practice almost all experts in the field suggest that 5 specific components should be included when obtaining IC: 1 . diagnosis; 2 . proposed treatment; 3. attendant risks and benefits of the treatment; 4 . alternative treatments and their risks and benefits; and 5. risks and benefits of declining treatment $[12,13,38,41,47]$.

\section{Ensuring capacity and offering appropriate disclosure}

A direct and unbiased dialogue between patient and physician is the mainstay of any IC. Adherence and compliance are optimized when patients understand 2 important factors: 1. the treatment goal, namely why he/she should take the recommended treatment; and 2. the basic characteristics of the drug, i.e. the route of administration, safety profile, potential adverse events, precautions to be taken, and documented effectiveness. Finally, an important factor required for a patient to make a decision includes knowledge of the clinical consequences that may ensue if he/she decides to stay untreated.

\section{Treatment goal}

The goal of any therapy should be well described and should include both objective medical endpoints and patients' expectations. This is a rapidly changing environment, as new short- and long-term therapeutic outcomes have been added to the goals of treatment for these lifelong diseases since the dawn of the biologic era. For instance, clinical remission should be confirmed by normalization of serum and fecal biomarkers and mucosal healing [55]. Histological remission is also emerging as a desirable target of therapy for patients with ulcerative colitis [56]. On the other hand, patients are not interested in medical minutiae and cannot understand terms like "deep remission" or "mucosal healing": patient-reported outcomes (PROs) are a useful aid in this direction. PROs illustrate and quantify symptoms, since they include severity scales for pain, 
urgency, and defecation [57]. Finally, physicians should remind patients of the possible consequences of non-adherence and lack of compliance by analyzing the natural history and the consequences of a disabling course of disease, without using intimidating expressions and inducing psychological terror.

\section{Basic characteristics of treatment}

i. Route and timetable of drug administration

This is an important parameter for the patient. Oral, subcutaneous or intravenous routes of administration have different characteristics, whilst most patients prefer long intervals between their therapies, to feel healthier and enjoy a beneficial quality of life. In addition, we have to take into account that older patients need assistance in coming to hospital for intravenous treatment and have a higher risk of catching nosocomial infections.

ii. Treatment efficacy

The description and explanation of the efficacy and effectiveness of treatment, as documented by Phase III and post-marketing authorization phase IV clinical trials (especially in real-world clinical studies), is essential during discussion of the therapeutic options with the patient. IBD is a chronic, disabling and incurable disease-a fact with which a patient must be fully conversant in order to have realistic expectations of his/her health in the longer term. Nevertheless, when discussing a treatment, it is important to enumerate the anticipated percentages of effectiveness. It is also important to emphasize that we use percentages to denote the effectiveness of treatment because, so far, we lack precise predictive markers for response to each treatment. Another factor that has to be clarified is the necessary duration until complete efficacy of treatment. Although clinical correspondence might be achieved in 1-2 weeks [58], complete efficacy and final clinical results of pharmaceutical treatment can only be ascertained after at least 8-10 weeks [59], so the patient must be advised not to be anxious and eager about the efficiency of treatment.

iii. Adverse events

The most difficult part of IC is to explain the possible hazards of treatment and the balance between risk and benefit, as thoroughly described above. Physicians have to be more descriptive about the risk of the treatment and specifically analyze the important elements of risk: 1 . the nature of the risk; 2 . the seriousness of the risk; 3 . the probability that the risk may occur; and 4 . the imminence of the risk (which can range from a few minutes to as long as decades after the start of the treatment) [60]. Patients should be informed about any side-effects with a high probability but low severity, as well as those with a very low probability but a high degree of severity [13]. An effective way to avoid patients' anxiety about the risk of serious complications is to analyze the above risk elements with simple rather than scary expressions, while focusing on the established immediate benefit of treatment compared to the small risk of serious side-effects [61]. An example of presenting adverse events is illustrated in Fig. 1.
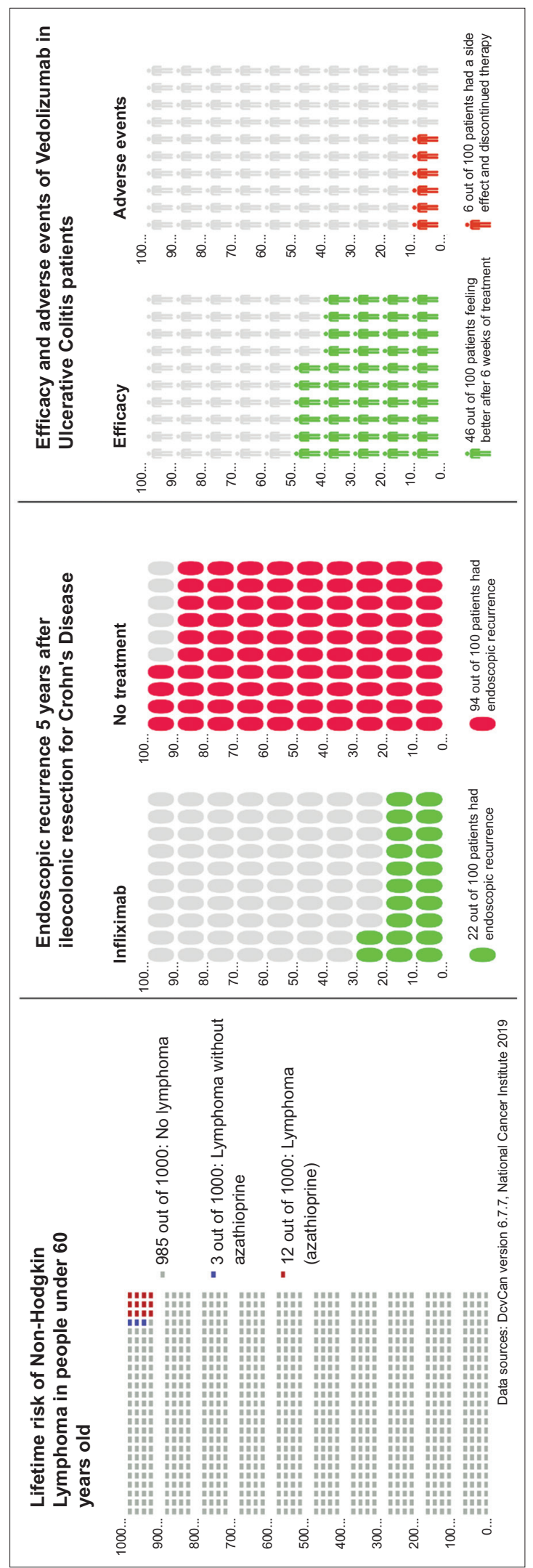

Figure 1 Icon array examples for inflammatory bowel disease patients Images created by Iconarray.com. Risk Science Center and Center for Bioethics and Social Sciences in Medicine, University of Michigan 
Assessing patient numeracy and literacy before listing any numbers and risk probabilities using the abovementioned approaches is important. Physicians are obligated to refer to the adverse events and their estimated absolute risks that are mentioned in the literature and are related to IBD treatment (Table 1) [62-72].

Special consideration has to be given to specific populations, such as children and older people. We are obligated to inform minors and their parents that, given the chronic nature of the disease, pharmaceutical treatment must be continued for a long period of time; consequently, they have to be very careful and

Table 1 Risk of adverse events of treatment for inflammatory bowel disease categorized by class of drug

\begin{tabular}{|c|c|}
\hline Medication & Adverse events \\
\hline $\begin{array}{l}\text { Steroids } \\
\text { [62-64] }\end{array}$ & $\begin{array}{l}\text { - Short-term: rashes (50\%), facial swelling (35\%), } \\
\text { weight gain, muscle weakness, depression or } \\
\text { anxiety (8\%), leukocytosis, gastrointestinal } \\
\text { discomfort } \\
\text { - Long-term: cataract and/or glaucoma }(9 \%) \text {, } \\
\text { osteoporosis (33\%), blood hypertension (13\%), } \\
\text { diabetes mellitus (chances increased } \times 10) \text {, } \\
\text { infections (13\%), growth impairment in children }\end{array}$ \\
\hline $\begin{array}{l}\text { Azathioprine } \\
\text { [65-67] }\end{array}$ & $\begin{array}{l}\text { - Severe leukopenia (10\%), pancreatitis (3\%), } \\
\text { impaired liver function tests ( } 2 \%) \text {, nausea } \\
\text { and/or epigastric pain ( } 2 \%) \text { (option to change } \\
\text { with 6-mercaptopurine), infections (5\%), stop } \\
\text { therapy due to adverse events ( } 11 \%) \\
\text { - Solid tumors, lympho-hyperplastic diseases, } \\
\text { mainly non-Hodgkin's lymphoma (0.04\%), non- } \\
\text { melanoma skin carcinoma }\end{array}$ \\
\hline $\begin{array}{l}\text { Methotrexate } \\
{[68]}\end{array}$ & $\begin{array}{l}\text { - Short-term: gastrointestinal symptoms (29\%), } \\
\text { fatigue or dizziness } \\
\text { - Long term: folate deficiency, infections, } \\
\text { impaired liver function tests (23\%), leukopenia } \\
\text { (8\%) and liver fibrosis (controversial) } \\
\text { - Most alarming adverse event: teratogenicity } \\
\text { (physicians should advise patients to take } \\
\text { efficient contraception measures) }\end{array}$ \\
\hline $\begin{array}{l}\text { Biologics } \\
{[67,69,70]}\end{array}$ & $\begin{array}{l}\text { - Injection-related local or systemic reactions, } \\
\text { immediate or delayed (3-21\%) } \\
\text { - Arthralgias, myalgias, drug-induced lupus-like } \\
\text { syndrome (1\%) } \\
\text { - Reactivation of latent infections (tuberculosis } \\
\text { and hepatitis B or C) } \\
\text { - Serious infections (3\%) } \\
\text { - Deterioration of heart failure and demyelination } \\
\text { syndromes (multiple sclerosis, optic neuritis) } \\
\text { - Malignancies (anti-tumor necrosis factor } \\
\text { agents): non-Hodgkin's lymphoma } 0.06 \% \text { (in } \\
\text { combination with azathioprine), melanoma or } \\
\text { cervical cancer } \\
\text { - Stop therapy because of adverse event (10\%) }\end{array}$ \\
\hline $\begin{array}{l}\text { Janus kinase } \\
\text { inhibitors } \\
\text { (Tofacitinib) } \\
{[71,72]}\end{array}$ & $\begin{array}{l}\text { - Allergic reactions } \\
\text { - Pulmonary embolism (blood clots in the lungs) } \\
\text { and other thrombotic conditions mainly in } \\
\text { patients with predisposing/aggravating factors } \\
(0.1-0.3 \%) \\
\text { - Herpes zoster in older people (4-7\%) } \\
\text { - Common and opportunistic infections }(3 \%)\end{array}$ \\
\hline
\end{tabular}

vigilant regarding adverse events or any peculiar symptoms. Older people and patients with many comorbidities, or in the presence of pretreatment frailty, appear to be at greater risk for treatment-related adverse events such as infections, as Kochar et al. showed in a recent study [73]. For this patient category, physicians could choose appropriate treatment with relatively fewer adverse events, e.g. vedolizumab or ustekinumab, and explain the reasons to patients.

\section{Presentation of essential information}

The main concern of physicians should not be to communicate the adverse effects of drugs to patients in a formal way, but rather to select the relevant information to communicate in the most understandable way. Visual aids efficiently communicate the real risks and benefits of a proposed treatment concurrently. IBD departments can easily make their own information sheets or visual aid brochures for their patients, using a plethora of tools that are commercially available electronically or via other sources, as illustrated in Fig. 1 (all numerical data and percentages originate from well-conducted, randomized studies or recent reviews) [74-77]. As mentioned earlier, icon arrays ("pictographs") have shown to be more effective than bar or pie charts at communicating medical data (e.g. risks or benefits of treatment). An example of 2 different visual aid versions of the same information is depicted in Fig. 2, where the results of the SONIC Study (The Study of Biologic and Immunomodulator Naïve Patients in Crohn's disease) are presented [78].

\section{Ensuring comprehension, voluntariness and adopting SDM}

The next step, after explaining all the aforementioned parameters and assessing patient understanding, is to share the decision making. This physician-dependent process aims at guiding patients to different treatment options in order to eventually choose the one that best fits their system of values or needs. The patient must feel confident about his/her ultimate choice. However, understanding all these complex benefits and risk profiles of pharmaceutical agents is often difficult and is a major cause of patients' psychosocial distress in the decision-making process. Physicians must be very careful about managing anxiety and psychological pressure. Visual aids or other audiovisual materials, such as brochures or videos, could increase patients' participation in their decisionmaking process, reduce conflicts regarding treatment plans and finally increase patient satisfaction $[79,80]$. Technological and internet evolution (including social media use, websites, web-based activities, etc.) can become a useful tool in the physician's arsenal in order to comprehensively inform their patients. An often reliable information source, which any patient should be encouraged to follow, is the local/national IBD Patients' Association (website, regular meetings, etc.). 


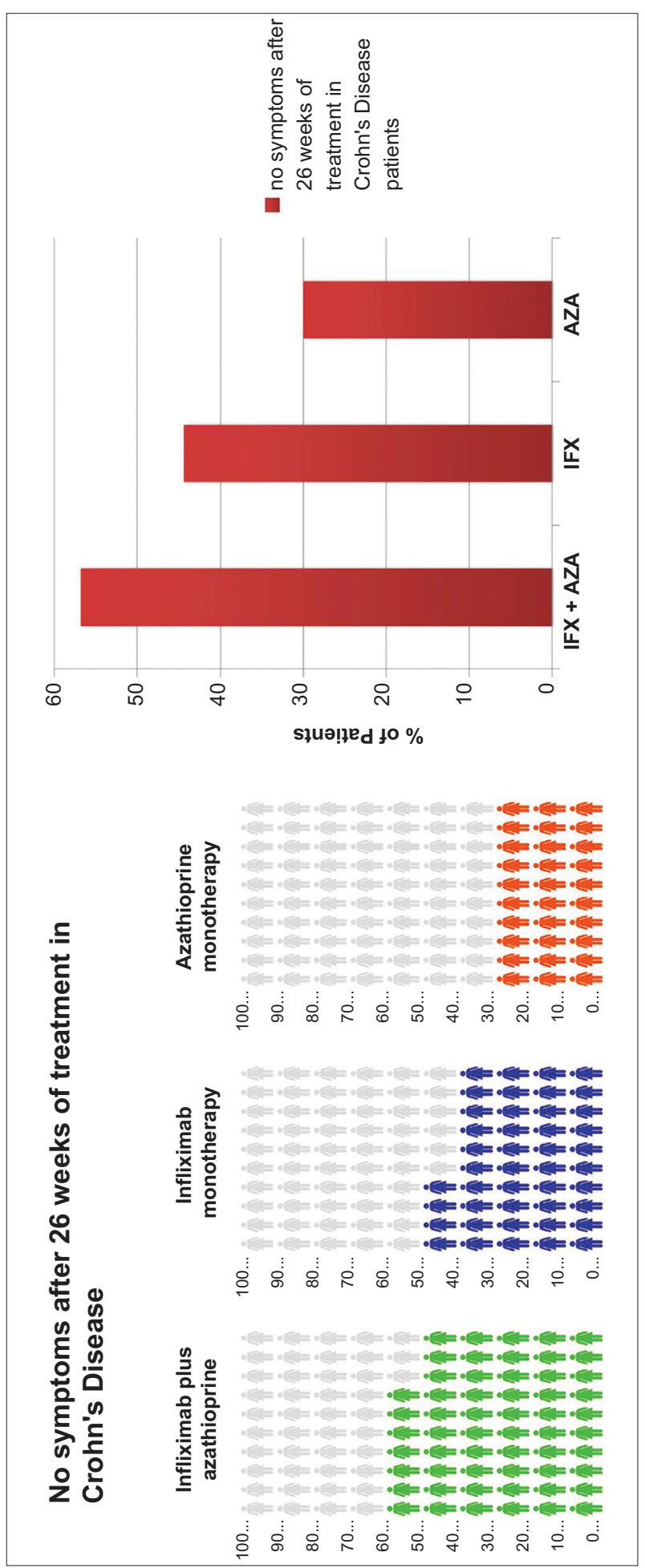

Figure 2 Icon array and bar charts illustrating some data from the SONIC study

These associations guarantee that objective information is shared, and provide a useful network of people who are dealing with the same problems and difficulties. Concurrently, care should be taken to steer patients away from bad counseling websites or misinformation from family, friends or social media about controversial treatment options. The patient has to realize that every IBD case has unique characteristics and no comparison with other apparently similar cases can be made, so as not to be biased against any kind of proposed treatment.

Two surveys of IBD patients, performed to explore how much risk patients are willing to accept, have yielded interesting results. When patients were given scenarios of severe disease and low quality of life, higher treatment risks were accepted in the expectation of a larger therapeutic benefit. Conversely, patients (or their parents in pediatric cases) with a recent diagnosis or a mild disease were not willing to accept the higher risks of the available biologic drugs [81,82]. Apart from the proposed pharmaceutical or surgical treatment, patients have to be informed about alternative options, such as temporarily not choosing any therapy ("wait-and-see" strategy), or being able to give up therapy at any time, after detailed information concerning the possible consequences of their choice.

It is important for patients to be informed that they may bring their relatives with them during the consultation if they are willing to share decision making, especially older patients or patients with cognitive impairment, etc. Moreover, minors, who make up a sizeable number of IBD patients, are not legally considered to have the capacity to consent to an intervention, so that consent may only be given by the patient's representative (parent) or another person authorized by law. Nevertheless, the opinion of the child/teenager should be taken into consideration with respect to his/her age and degree of maturity. In addition, it is our opinion that a second physician of the IBD team or a specialist IBD nurse should be present throughout the aforementioned process.

Sharing the decision-making process helps clarify the patient's understanding of their diagnosis and proposed treatment, while it identifies his/her priorities and goals. It also determines his/her desirable health status, so that the physician has the ability to choose the best individually tailored treatment [9].

\section{The dilemma of documentation of IC}

Consent may be expressed verbally or non-verbally: an example of non-verbal consent would be where a person, after receiving appropriate information, holds out his/her arm for blood examination, or in our case proceeds to the gastroenterology department for drug infusion. Clinicians have the option to document the content of the discussion with their patients on their medical records, to provide evidence of their conversation or to use it as risk management tool, for the patient who has understood and accepted the possibility of potential adverse events associated with a treatment.

Studies of the validity of IC forms involve interventional procedures, such as surgery, anesthesia, radiographic imaging with intravenous contrast, chemotherapy, endoscopic procedures, electroconvulsive therapy and cardiac catheterization $[28,83]$. 
As there are no published guidelines or evidence-based recommendations in the literature so far, we cannot suggest that it is mandatory for physicians to seek their patients' written and signed approval before prescribing an IBD regimen. Whether to adopt an IC form is a decision that directors of gastroenterology departments or individual physicians in the private sector must take for themselves, according to the local legal, ethical and compliance standards, and we do not recommend either for or against it. In the case that an IBD Department decides to adopt IC forms, it is strongly recommended to obtain consent for immunosuppressants and biologics, since these are the drugs that have more serious, although extremely rare, adverse events, such as lymphomas, tuberculosis exacerbation, demyelinating disorders, etc. For more commonly used regimens, such as 5-aminosalicylates, verbal consent is sufficient.

A validated IC form must fulfill the minimal requirements described above and should conform to specific local circumstances. It should contain only basic information about the risks of the treatment in a simple and understandable manner, the probability and rates of remission after treatment, and the consequences of choosing to remain untreated. It needs to be accurate, free of jargon and formatted appropriately, to be read easily. Procedural issues, such as the route of administration or preemptive examinations required before starting treatment, could be excluded from the form in order to increase the readability. The overall readability score of a consent form should be assessed using the FRES and targeting a score of more than 60 (i.e. what we would expect to be understood by a child aged 12-15 years old).

One main purpose of obtaining evidence of consent, through a form or in medical record files, is to determine the exact terms of medical consent in the case of a future dispute or lawsuit. The specificity, comprehensiveness and completeness of the signed form helps protect the physician or the institution from undesirable legal consequences. However, the mere presence of a form alone does not prove that the content was delivered properly. Rather, it is a proof that a consent process had indeed taken place [84]. All the above-mentioned conclusions have been summarized as brief recommendations for IBD physicians in Table 2.

\section{Concluding remarks}

Treatments for IBD, mainly biologic or immunomodulator therapies, carry significant risks, making interactivity and complete illustration crucial for decision making in clinical practice. IC is not only applicable to medical procedures like surgery or endoscopy, but is necessary for all significant management decisions, such as the administration of the aforementioned drugs to IBD patients.

Despite the importance of ensuring patients' health literacy and readability, unfortunately the overreliance on written information and signed consent forms seems outdated. Ultimately, a productive conversation remains the cornerstone of an IC procedure, where a physician analyzes the treatment's goals, its basic characteristics, potential adverse events (mild to
Table 2 Recommendations for a valid informed consent

Use comprehensible and simple language
Avoid statistical and technical details
Inform the patient in the most convenient surroundings
Define and prioritize the goals of treatment according to the
patient's life goals
Provide written material, so that the patient can study the issues
involved
Develop a practice of sharing decision making
Ensure constantly during the informed consent procedure patient's:
- Capacity
- Comprehension (always ask for any questions)
- Voluntary choice free of influence
Be explicit and descriptive about risks of treatment. Especially:
- The nature of the risk
- The probability that the risk may occur
- The severity of the risk
- The proximity of the risk (a few minutes or years later)
Include statements alluding to the small risk of severe complications
in comparison with the treatment's established benefit
Document the process:
- Signed consent form (not a prerequisite)
- Educational materials (written, web-based, electronic)
- Notes on patient's medical record describing the therapeutic plan,
risks and benefits

severe, common to very rare), while allowing sufficient time for queries. Special attention should be paid to patients with poor literacy skills, visual impairment, and language barriers.

This review aimed at highlighting the importance of an IC procedure in routine real-world clinical practice in the field of IBD and proposing an appropriate way of informing our IBD patients, to gain their consent to proposed medical treatments with regard to the principles of medical ethics, but also to emergent legal conflicts. An unresolved question is whether the adoption of a signed consent protocol is practical and has benefits other than to protect physicians from liability suits. However, the legal standards that apply to obtaining IC vary across jurisdictions, and their interpretation continues to evolve. Apart from that, it was not the object of our study.

Unfortunately, physicians do not receive adequate training on how to conduct IC discussions [85]. Therefore, it is time for national and international IBD societies to initiate appropriate training activities to improve physicians' communication skills and to plan advisory boards and consensus meetings to establish universally implemented IC procedures. The patient's motivation to participate in joint decision making is undoubtedly a key factor for a better physician-patient relationship and improved treatment compliance rates.

\section{References}

1. Shah P, Thornton I, Turrin D, Hipskind JE. Informed Consent. In: StatPearls [Internet]. Treasure Island (FL): StatPearls Publishing; 
2020 Jan-. Available from: https://www.ncbi.nlm.nih.gov/books/ NBK430827

2. Ethics manual. Fourth edition. American College of Physicians. Ann Intern Med 1998;128:576-594.

3. Greek medicine - the Hippocratic oath. U.S. National Library of Medicine, 8600 Rockville Pike, Bethesda, 2002.

4. AMA, editor. Obligation of patients to their physicians. In: Code of Medical Ethics. American Medical Association, Chicago 1847.

5. Salgo v. Leland Stanford Etc. Bd. Trustees, 317 P.2d 170 (Cal. Ct. App. 1957).

6. Natanson v. Kline, 350 P.2d 1093 (Kan. 1960).

7. World Medical Assembly 34. World Medical Association declaration of Lisbon on the rights of the patient. Adopt by 34 World Med Assem Lisbon, Port, 1981.

8. Convention for the protection of human rights and dignity of the human being with regard to the application of biology and medicine: Convention on Human Rights and Biomedicine. Oviedo, 1997.

9. Hall DE, Prochazka AV, Fink AS. Informed consent for clinical treatment. Can Med Assoc J 2012;184:533-540.

10. Boyd K. The impossibility of informed consent? J Med Ethics 2015;41:44-47.

11. Katz J. Informed consent-must it remain a fairy tale? J Contemp Heal Law Policy 1994;10:69-91.

12. The Joint Commission. In: 2009 hospital accreditation standards. Oakbrook T. The Commission, Illinois, 2009.

13. Patients' rights and the basic principles of consent. Consent manual 2020. $47^{\text {th }}$ Edition, Chapter 2, California Hospital Association.

14. Opinions on consent, communication and decision making. Chapter 2. In: American Medical Association Code of Medical Ethics 2016, pp. 1-2.

15. Garcia-Retamero R, Sobkow A, Petrova D, Garrido D, Traczyk J. Numeracy and risk literacy: what have we learned so far? Span J Psychol 2019;22:E10.

16. Davids SL, Schapira MM, McAuliffe TL, Nattinger AB. Predictors of pessimistic breast cancer risk perceptions in a primary care population. J Gen Intern Med 2004;19:310-315.

17. Schwartz LM, Woloshin S, Black WC, Welch HG. The role of numeracy in understanding the benefit of screening mammography. Ann Intern Med 1997;127:966-972.

18. Lipkus IM, Samsa G, Rimer BK. General performance on a numeracy scale among highly educated samples. Med Decis Making 2001;21:37-44.

19. Ratzan SC, Parker RM. Introduction. In: Selden CR, Zorn M, Ratzan SC, Parker RM, editors. In National Library of Medicine current bibliographies in medicine: Health literacy. Bethesda, MD: National Institutes of Health; 2000.

20. Berkman ND, Sheridan SL, Donahue KE, Halpern DJ, Crotty K. Low health literacy and health outcomes: an updated systematic review. Ann Intern Med 2011;155:97-107.

21. America's health literacy: why we need accessible health information. An Issue Brief from the U.S Department of Health and Human Services, 2008.

22. Yin HS, Dreyer BP, van Schaick L, Foltin GL, Dinglas C, Mendelsohn AL. Randomized controlled trial of a pictogrambased intervention to reduce liquid medication dosing errors and improve adherence among caregivers of young children. Arch Pediatr Adolesc Med 2008;162:814-822.

23. Garcia-Retamero R, Cokely ET. Communicating health risks with visual aids. Curr Dir Psychol Sci 2013;22:392-399.

24. Edwards A, Elwyn G, Mulley A. Explaining risks: turning numerical data into meaningful pictures. BMJ 2002;324:827-830.

25. Lipkus IM. Numeric, verbal, and visual formats of conveying health risks: suggested best practices and future recommendations. Med Decis Making 2007;27:696-713.
26. Paling J. Strategies to help patients understand risks. BMJ 2003;327:745-748.

27. Garcia-Retamero R, Cokely ET. Designing visual aids that promote risk literacy: a systematic review of health research and evidencebased design heuristics. Hum Factors 2017;59:582-627.

28. Glaser J, Nouri S, Fernandez A, et al. Interventions to improve patient comprehension in informed consent for medical and surgical procedures: an updated systematic review. Med Decis Making 2020;40:119-143.

29. Flesch R. How to Test Readability. Harper and Row: New York; 1951.

30. Flesch R. A new readability yardstick. J Appl Psychol 1948;32:221-233.

31. Sivanadarajah N, El-Daly I, Mamarelis G, Sohail MZ, Bates P. Informed consent and the readability of the written consent form. Ann R Coll Surg Engl 2017;99:645-649.

32. Badarudeen S, Sabharwal S. Assessing readability of patient education materials: current role in orthopaedics. Clin Orthop Relat Res 2010;468:2572-2580.

33. Myers ED, Calvert EJ. The effect of forewarning on the occurrence of side-effects and discontinuance of medication in patients on amitriptyline. Br J Psychiatry 1973;122:461-464.

34. Myers ED, Calvert EJ. The effect of forewarning on the occurrence of side-effects and discontinuance of medication in patients on dothiepin. J Int Med Res 1976;4:237-240.

35. Myers ED, Calvert EJ. Knowledge of side effects and perseverance with medication. Br J Psychiatry 1978;132:526-527.

36. Keown CF, Slovic P, Lichtenstein S. Influence of information about side effects on perceived risks of prescription drugs. Health Mark $Q$ 1983-1984;1:111-123.

37. Myers MG, Cairns JA, Singer J. The consent form as a possible cause of side effects. Clin Pharmacol Ther 1987;42:250-253.

38. Rapp MS. Informed consent and phobias. CMAJ 1986;135:435.

39. Berg J, Appelbaum P, Lidz C, Parke L. Informed consent: legal theory and clinical practice. $2^{\text {nd }}$ ed., 2001.

40. Quaid KA, Faden RR, Vining EP, Freeman JM. Informed consent for a prescription drug: impact of disclosed information on patient understanding and medical outcomes. Patient Educ Couns 1990;15:249-259.

41. Reference guide to consent for examination or treatment. $2^{\text {nd }} e d$., Department of Health,UK, 2009.

42. National Code of Medical Ethics Reference, Greek Law 3418/2005.

43. Park BY, Kwon J, Kang SR, Hong SE. Informed consent as a litigation strategy in the field of aesthetic surgery: an analysis based on court precedents. Arch Plast Surg 2016;43:402-410.

44. Supreme Court of South Korea Decision No. 94 Da 35671.

45. Hickson GB, Federspiel CF, Pichert JW, Miller CS, GauldJaeger J, Bost P. Patient complaints and malpractice risk. JAMA 2002;287:2951-2957.

46. Levinson W. Physician-patient communication. The relationship with malpractice claims among primary care physicians and surgeons. JAMA 1997;277:553-559.

47. Informed consent for clinical treatments and procedures. Department of Veterans Affairs Veterans Health Administration Washington, DC 20420. VHA HANDBOOK 1004.01(4), 2009. Amended January 4, 2021.

48. Marques Filho J. Informed consent in rheumatology care practice. Rev Bras Reumatol 2011;51:179-183.

49. Storm C, Casillas J, Grunwald H, Howard DS, McNiff K, Neuss MM. Informed consent for chemotherapy: ASCO Member Resources. J Oncol Pract 2008;4:289-295.

50. Treleaven J, Cullis JO, Maynard R, et al.; British Committee for Standards in Haematology. Obtaining consent for chemotherapy. Br J Haematol 2006;132:552-559.

51. Kurin M, Katz J, Kodish E, Lashner B. Informed consent in IBD trials: where we are and where we need to go. Inflamm Bowel Dis 
2019;25:1115-1119.

52. Picoraro JA, Rosh JR. Communicating the benefits and risks of inflammatory bowel disease therapy to patients and families. Curr Opin Pediatr 2017;29:572-577.

53. Siegel CA, Lofland JH, Naim A, et al. Gastroenterologists' views of shared decision making for patients with inflammatory bowel disease. Dig Dis Sci 2015;60:2636-2645.

54. Siegel CA. Lost in translation: helping patients understand the risks of inflammatory bowel disease therapy. Inflamm Bowel Dis 2010;16:2168-2172.

55. Colombel JF, Panaccione R, Bossuyt P, et al. Effect of tight control management on Crohn's disease (CALM): a multicentre, randomised, controlled phase 3 trial. Lancet 2017;390:2779-2789.

56. Lobatón T, Bessissow T, Ruiz-Cerulla A, et al. Prognostic value of histological activity in patients with ulcerative colitis in deep remission: A prospective multicenter study. United European Gastroenterol J 2018;6:765-772.

57. Peyrin-Biroulet L. What is the patient's perspective: How important are patient-reported outcomes, quality of life and disability? Dig Dis 2010;28:463-471.

58. Laharie D, Bourreille A, Branche J, et al.; Groupe d'Etudes Thérapeutiques des Affections Inflammatoires Digestives. Ciclosporin versus infliximab in patients with severe ulcerative colitis refractory to intravenous steroids: a parallel, open-label randomised controlled trial. Lancet 2012;380:1909-1915.

59. Rutgeerts P, Sandborn WJ, Feagan BG, et al. Infliximab for induction and maintenance therapy for ulcerative colitis. $\mathrm{N} \mathrm{Engl} \mathrm{J}$ Med 2005;353:2462-2476.

60. Feld AD. Informed consent: not just for procedures anymore. Am J Gastroenterol 2004;99:977-980.

61. Karsli T, Kalra MK, Self JL, Rosenfeld JA, Butler S, Simoneaux S. What physicians think about the need for informed consent for communicating the risk of cancer from low-dose radiation. Pediatr Radiol 2009;39:917-925.

62. Present DH. How to do without steroids in inflammatory bowel disease. Inflamm Bowel Dis 2000;6:48-57.

63. Rutgeerts PJ. Review article: the limitations of corticosteroid therapy in Crohn's disease. Aliment Pharmacol Ther 2001;15:15151525.

64. Rutgeerts P, Löfberg R, Malchow $\mathrm{H}$, et al. A comparison of budesonide with prednisolone for active Crohn's disease. $\mathrm{N} \mathrm{Engl} \mathrm{J}$ Med 1994;331:842-845.

65. Siegel CA, Sands BE. Review article: practical management of inflammatory bowel disease patients taking immunomodulators. Aliment Pharmacol Ther 2005;22:1-16.

66. Present DH, Meltzer SJ, Krumholz MP, Wolke A, Korelitz BI. 6-Mercaptopurine in the management of inflammatory bowel disease: short- and long-term toxicity. Ann Intern Med 1989;111:641-649.

67. Siegel CA, Marden SM, Persing SM, Larson RJ, Sands BE. Risk of lymphoma associated with combination anti-tumor necrosis factor and immunomodulator therapy for the treatment of Crohn's disease: a meta-analysis. Clin Gastroenterol Hepatol 2009;7:874-881.

68. McKendry RJ, Dale P. Adverse effects of low dose methotrexate therapy in rheumatoid arthritis. J Rheumatol 1993;20:1850-1856.

69. Siegel C. The risks of biologic therapy for inflammatory bowel disease. In: Bernstein C, editor. The Inflammatory Bowel Disease Yearbook. $6^{\text {th }}$ ed. London: Remedica, 2009.

70. Vermeire S, Noman M, Van Assche G, et al. Autoimmunity associated with anti-tumor necrosis factor alpha treatment in Crohn's disease: a prospective cohort study. Gastroenterology 2003;125:32-39.

71. Sandborn WJ, Panés J, Panaccione R, et al. A202 Tofacitinib for the treatment of ulcerative colitis: up to 5.4 years of safety data from global clinical trials. J Can Assoc Gastroenterol 2019;2(Suppl 2):396-397.

72. Harigai M. Growing evidence of the safety of JAK inhibitors in patients with rheumatoid arthritis. Rheumatology (Oxford) 2019;58(Suppl 1):i34-i42.

73. Kochar B, Cai W, Cagan A, Ananthakrishnan AN. Pretreatment frailty is independently associated with increased risk of infections after immunosuppression in patients with inflammatory bowel diseases. Gastroenterology 2020;158:2104-2111.

74. Regueiro M, Kip KE, Baidoo L, Swoger JM, Schraut W. Postoperative therapy with infliximab prevents long-term Crohn's disease recurrence. Clin Gastroenterol Hepatol 2014;12:1494-1502.e1.

75. Narula N, Peerani F, Meserve J, et al. Vedolizumab for ulcerative colitis: treatment outcomes from the VICTORY consortium. Am J Gastroenterol 2018;113:1345.

76. Bewtra M, Lewis JD. Update on the risk of lymphoma following immunosuppressive therapy for inflammatory bowel disease. Expert Rev Clin Immunol 2010;6:621-631.

77. Feagan BG, Rutgeerts P, Sands BE, et al.; GEMINI 1 Study Group. Vedolizumab as induction and maintenance therapy for ulcerative colitis. N Engl J Med 2013;369:699-710.

78. Colombel JF, Sandborn WJ, Reinisch W, et al.; SONIC Study Group. Infliximab, azathioprine, or combination therapy for Crohn's disease. N Engl J Med 2010;362:1383-1395.

79. Glass KE, Wills CE, Holloman C, et al. Shared decision making and other variables as correlates of satisfaction with health care decisions in a United States national survey. Patient Educ Couns 2012;88:100-105.

80. Lim E. Patients' perspective in the surgical decision-making process. Thorac Surg Clin 2012;22:539-543.

81. Johnson FR, Özdemir S, Mansfield C, et al. Crohn's disease patients' risk-benefit preferences: serious adverse event risks versus treatment efficacy. Gastroenterology 2007;133:769-779.

82. Johnson FR, Özdemir S, Mansfield C, Hass S, Siegel CA, Sands BE. Are adult patients more tolerant of treatment risks than parents of juvenile patients? Risk Anal 2009;29:121-136.

83. Nejadsarvari N, Ebrahimi A. Different aspects of informed consent in aesthetic surgeries. World J Plast Surg 2014;3:81-86.

84. Paterick TJ, Carson GV, Allen MC, Paterick TE. Medical informed consent: general considerations for physicians. Mayo Clin Proc 2008;83:313-319.

85. McClean KL, Card SE. Informed consent skills in internal medicine residency: how are residents taught, and what do they learn? Acad Med 2004;79:128-133. 